\title{
Editorials
}

\section{Improving GP registration and access for migrant health}

\section{INTRODUCTION}

Migrants to the UK - including refugees, asylum seekers, and undocumented migrants - experience health inequities due to social exclusion, discrimination, language barriers, and, for some, restricted entitlement to health care due to their immigration status. ${ }^{1}$ In this article we echo recent calls for more inclusive migrant health care $^{2}$ and consider the impacts of COVID-19 on access to primary care for undocumented migrants in particular.

\section{MIGRANTS IN VULNERABLE CIRCUMSTANCES IN THE UK}

A recent report estimated that there are 674000 undocumented migrants across the UK, with 397000 in London. ${ }^{3}$ The number of undocumented children in the UK increased by 79\% between 2011 and 2017, and almost half were born in the UK. ${ }^{3}$ Home Office statistics show that, every year, approximately 30000 asylum applications are lodged and roughly 20000 of these are granted asylum, alternative forms of leave, or resettlement. ${ }^{4}$ These figures show that there are many migrants who do not have a secure immigration status, right to work, or access to welfare services leaving them with inadequate housing and potential destitution. These vulnerable situations make it difficult for migrants to access the healthcare services they need, despite many having additional healthcare needs (see Box 1).

\section{IMPACT OF COVID-19}

The COVID-19 pandemic has highlighted the need for a more inclusive approach in the way health services are provided. A recent systematic review found that migrants are at increased risk of contracting COVID-19.10 A detailed analysis by Doctors of the World (DOTW) of the early impacts of the pandemic on excluded people in England showed that COVID-19 created new destitution and homelessness, particularly among those with no recourse to public funds. ${ }^{11}$ The report revealed that de-registration of patients who have been temporarily housed outside their catchment areas or who are socially distancing/isolating at an alternative address affected many marginalised people's healthcare access to (and trust in) health services and created delays in access to medications such as antidepressants, creating additional barriers to care. ${ }^{11}$

During the pandemic, the DOTW clinics witnessed the vulnerable circumstances many migrants have been living in and the ongoing barriers to accessing primary care. While $44 \%$ of patients who attended DOTW clinics during the 3 -month period prior to the first lockdown stated that they have inadequate or insecure housing, this figure increased to $60 \%$ in the 3-month period starting with the first lockdown, showing the impact on housing. ${ }^{12}$ Furthermore, of the 927 patients attending during 2020, 407 $(44 \%)$ reported that they could not access health care due to ongoing barriers. Of

\section{Box 1. Additional health needs of migrants}

Migrant populations are diverse but many face a 'triple burden' of non-communicable diseases, infectious diseases, and mental health problems due to a range of adverse experiences before, during, and after migration. ${ }^{5}$

- Non-communicable diseases: The World Health Organisation (WHO) reports that refugees and migrants have a higher incidence, prevalence, and mortality rate for chronic conditions such as diabetes, and that cancer is more likely to be diagnosed at an advanced stage in refugees and migrants. ${ }^{6} \mathrm{~A}$ UK report also reported poorer physical health outcomes due to experiences during and after migrating to the UK?

- Infectious diseases: Some infectious diseases are more common in other countries due to different health systems and vaccination programmes. Also, living in overcrowded conditions with poor sanitation before, during, and after migration increases risks of bacterial, viral, and parasitic infections. The UN programme on HIV and AIDS recognises that displacement and migration can place people in situations of heightened vulnerability to HIV.

- Mental health: People seeking asylum are more likely to experience mental health problems than the general population, including post-traumatic stress disorder and longer-term effects of inhumane treatment such as torture and sexual violence. ${ }^{8}$ Depression and anxiety are also commonly reported, linked to lengthy asylum-seeking processes and poor socioeconomic conditions such as unemployment or isolation.?

these, 258 (28\% of total) stated that they lack understanding or knowledge of their health rights and the healthcare system in the UK, 103 (11\%) faced administrative barriers such as inability to show proof of ID or address, and $73(8 \%)$ declared that they feared arrest or immigration enforcement in the healthcare services. The figures were all increases from previous years' statistics lunpublished data, DOTW, available from authors on request).

The reconfiguration of primary care towards 'remote-by-default' consulting, ${ }^{13}$ primarily by telephone, represents a further potential barrier to accessing care for migrant populations. The DOTW report found that many migrants lack access and skills to use technology or are unable to pay for access to broadband or mobile data. ${ }^{11}$ The reduced physical access to surgeries has also resulted in reduced support with registration, attendance, and signposting to other services, alongside challenges with communication and identifying safeguarding issues. ${ }^{14}$

\section{THE ROLE OF PRIMARY CARE}

General practice has played a key role in efforts to tackle health inequities among migrant populations. Primary care policy is clear that in England, Scotland, and Wales, immigration status should not affect entitlement to register for and receive primary care services. The NHS England Primary Medical Care Policy and Guidance Manual clearly states that lack of proof of identity or address would not be considered reasonable grounds to refuse to register a patient. ${ }^{15}$ This is encouraging, but further actions need to be taken to ensure the guidance is implemented. Similarly, NHS Scotland and NHS Wales should issue clear and accessible guidance and effective communication to GP practices to ensure inclusive access to migrants and other marginalised communities.

More recently, NHS England launched a new GP registration campaign highlighting that everyone is welcome in General Practice', accompanied by resources for patients to show their entitlements when they present at general practice for registration. ${ }^{16}$ This could play a role in addressing the pandemic too, as GP registration is one of the most effective ways of enabling access to the COVID-19 vaccine. However, inclusive policy often has a limited 
impact on the ground due to discrimination and social exclusion of migrants. ${ }^{17}$ The UK government's new Nationality and Immigration Bill, which proposes to penalise irregular entry to the UK asylum protection system, is likely to exacerbate barriers to access primary care. ${ }^{18}$

Examples of good inclusive registration practice should be recognised and shared widely. DOTW's Safe Surgeries Initiative is an innovative evidence-based programme that promotes a 'community of practice' model to tackle barriers to primary care and health inequalities faced by migrants. ${ }^{19}$ More than 600 general practices have signed up to the Initiative, ${ }^{18}$ which includes free training and access to expert advice on migrants' entitlement to health care, resources like translated posters, and a toolkit that helps address administrative and trust barriers. ${ }^{20}$ Finally, patient advocacy resources, similar to NHS England's GP Access cards, ${ }^{21}$ can help migrant groups know their rights and entitlements to health care, providing practical guidance on how to access services.

\section{CONCLUSION}

Many migrants - and undocumented migrants in particular - already face barriers to accessing primary care and are at increased risk of digital exclusion too. We join others in calling for targeted additional support to improve access to services, and engagement with local migrant community groups to provide clear, concise, and language-specific written and non-written resources. ${ }^{14}$ This will be important to facilitate COVID-19 vaccine uptake but is also critical for inclusive migrant health.

\section{Yusuf Ciftci,}

Policy and Advocacy Manager, Doctors of the World UK, London.

\section{David N Blane,}

IORCID: 0000-0002-3872-3621) Clinical Research Fellow in General Practice and Primary Care, General Practice and Primary Care, Institute of Health and Wellbeing, University of Glasgow. Glasgow.

\section{Open access}

This article is Open Access: CC BY 4.0 licence (http:// creativecommons.org/licences/by/4.0/1.

\section{ADDRESS FOR CORRESPONDENCE}

\section{David N Blane}

General Practice and Primary Care, Institute of Health and Wellbeing, University of Glasgow, 1 Horselethill Road, Glasgow G12 9LT, UK.

\section{Email: david.blanelaglasgow.ac.uk} adnblane

\section{Provenance}

Freely submitted; externally peer reviewed.

\section{Competing interests}

Yusuf Cliftci is policy and advocacy manager for Doctors of the World UK. David N Blane is an academic GP and is academic lead for the Deep End GP group in Scotland. The authors alone are responsible for the views expressed in this article, which do not necessarily represent the views, decisions, or policies of the institutions with which the authors are affiliated.

DOI: https://doi.org/10.3399/bjgp22X718301

\section{REFERENCES}

1. Kang C, Tomkow L, Farrington R. Access to primary health care for asylum seekers and refugees: a qualitative study of service user experiences in the UK. Br J Gen Pract 2019 DOI: https://doi.org/10.3399/bjgp19X701309.

2. Spitzer DL, Torres S, Zwi AB, et al. Towards inclusive migrant healthcare. BMJ 2019; 366: 14256 .

3. Jolly A, Thomas S, Stanyer J. London's children and young people who are not British citizens: a profile. 2020. https://muw.london.gov.uk/ sites/default/files/final_londons_children_and young people who are not british citizens.pdf laccessed 20 Dec 2021).

4. Home Office. How many people do we grant asylum or protection to? 2021. https://www.gov. uk/government/statistics/immigration-statisticsyear-ending-december-2020/how-manypeople-do-we-grant-asylum-or-protection-to (accessed 20 Dec 2021).

5. Abbas M, Aloudat T, Bartolomei J, et al. Migrant and refugee populations: a public health and policy perspective on a continuing global crisis. Antimicrob Resist Infect Control 2018; 7: 113.

6. World Health Organization. Report on the health of refugees and migrants in the WHO European Region: no public health without refugee and migrant health. 2018. https://apps.who.int/iris/bitstream/hand le/10665/311347/9789289053846-eng.pdf (accessed 20 Dec 2021).

7. Jayaweera $\mathrm{H}$. Health of migrants in the UK: what do we know? 2011. https://muw.bl.uk/ collection-items/health-of-migrants-in-the-ukwhat-do-we-know (accessed 20 Dec 2021).

8. World Health Organization. Mental health promotion and mental health care in refugees and migrants: technical guidance. 2018. https://uww.euro.who.int/_data/assets/ pdf file/0004/386563/mental-health-eng.pdf laccessed 20 Dec 2021)

9. Tribe R. Mental health of refugees and asylum seekers. Advances in Psychiatric Treatment 2002; 8(4): 240-247.

10. Hayward SE, Deal A, Cheng C, et al. Clinical outcomes and risk factors for COVID-19 among migrant populations in high-income countries: a systematic review. J Migr Health 2021; 3: 100041

11. Doctors of the World. A rapid needs assessment of excluded people in England during the 2020 COVID-19 pandemic. 2020. https:// uww.doctorsoftheworld.org.uk/wp-content/ uploads/2020/06/covid-full-rna-report.pdf (accessed 20 Dec 2021).

12. Lessard-Phillips L, Fu L, Lindenmeyer $A$ Phillimore J. Barriers to wellbeing: migration and vulnerability during the pandemic. 2021. https://uww.doctorsoftheworld.org.uk/ wp-content/uploads/2021/09/Barriers-towellbeing-09.21.pdf (accessed 6 Jan 2021)

13. Thornton J. Covid-19: how coronavirus will change the face of general practice forever. BMJ 2020; 368: $\mathrm{m} 1279$

14. Knights F, Carter J, Deal A, et al. Impact of COVID-19 on migrants' access to primary care and implications for vaccine roll-out: a national qualitative study. Br J Gen Pract 2021; DOI: https://doi.org/10.3399/BJGP.2021.0028.

15. NHS England, NHS Improvement. Primary Medical Care Policy and Guidance Manual (PGM). 2021. https://umw.england.nhs.uk/ publication/primary-medical-care-policy-andguidance-manual-pgm (accessed 20 Dec 2021).

16. Collison K. Everyone is welcome in General Practice. 2021. https://www.england.nhs.uk/ blog/everyone-is-welcome-in-general-practice laccessed 20 Dec 2021).

17. Campos-Matos I, Stannard J, de Sousa E, et al. From health for all to leaving no-one behind: public health agencies, inclusion health, and health inequalities. Lancet Public Health 2019: 4(12): e601-e603.

18. Gower M. Research briefing: Nationality and Borders Bill, Bill 141 of 2021-22. 2021. https:// commonslibrary.parliament.uk/researchbriefings/cbp-9275 (accessed 20 Dec 2021).

19. Doctors of the World. Safe Surgeries Initiative. https://www.doctorsoftheworld.org.uk/what-westand-for/supporting-medics/safe-surgeriesinitiative laccessed 20 Dec 2021).

20. Doctors of the World. Safe Surgeries Initiative: toolkit for COVID-19 response. 2020. https:// unw.doctorsoftheworld.org.uk/wp-content uploads/2020/09/DOTW_Safe-Surgeries-Toolkitfor-Covid-19-Response.pdf laccessed $20 \mathrm{Dec}$ 2021).

21. Doctors of the World. GP Access Cards. 2021. https://wnw.doctorsoftheworld.org.uk/ gp-access-cards (accessed 20 Dec 2021) 